\title{
AN INVESTIGATION INTO BACILLAEMIA IN LEPROSY
}

\author{
By R. RHODES-JoNES \\ East African Leprosy Research Centre \\ Alupe, Kenya
}

Postal Address: Box 1044, Busia, Tororo, Uganda.

Recent literature contains few references to the subject of bacillaemia in leprosy. MANSON-BAHR (1954) states that Mycohacterium leprae have been found occasionally either free in the blood or engulfed in leucocytes. IYENGAR (1919) found acid-fast bacilli in the mononuclear leucocytes in venous blood. SHTEIN and TUTKEVICH (1957) detected $M$. leprae in 115 out of 226 thick blood films prepared from finger-prick blood in 59 patients with lepromatous leprosy. Earlier literature has been reviewed by Lowe (1933) who describes a technique for concentrating the bacilli in a sample of venous blood, which was more reliable than the thick film method. By the concentration technique acid-fast bacilli were detected in 2 out of 23 cases of neural leprosy (tuberculoid) while in 51 cutaneous leprosy (lepromatous) 28 were found to have $M$. leprae in venous blood.

LowE (1933) points out that the thick film method is unreliable and that positive results obtained by this method may be false, bacilli from the skin itself contaminating the smear. He also considered that contamination of venous blood from the skin might also occur during the venepuncture and this might invalidate the results.

This paper presents the results of examination of venous blood in patients at the Alupe Leprosarium.

\section{Methods}

Venous blood $(2 \mathrm{ml}$.) was obtained from the median basilic vein in 101 cases of leprosy. The blood was expelled into a McCartney bottle containing oxalate. After thorough mixing, a drop of blood was placed on a slide and a thick smear prepared. The smear was dried at $37^{\circ} \mathrm{C}$ in an incubator and then stained by the RHODES-JONES (1959) modification of the Ziehl-Neelsen method.

In two patients the vein was exposed surgically before obtaining blood from the vein.

In six patients with a large number of acid-fast bacilli in the venous blood a needle was inserted of a sterile $2 \mathrm{ml}$. syringe, containing $0.5 \mathrm{ml}$. normal saline, parallel to the median basilic vein but without puncturing it. The contents of the syringe and needle was washed out into a McCartney bottle; the outside of the needle also being rinsed in the saline. All the fluid was then slowly evapora- 
ted drop by drop on to a heated albuminised slide and stained in the manner described. The whole smear was examined.

All techniques were carried out with aseptic precautions, and all bottles and syringes sterilised.

\section{Results}

The results of the examination of the venous blood of 101 patients with leprosy are given in Table 1.

In the patients from whom venous blood was obtained after surgical exposure of the vein, seventeen acid-fast bacilli were found in the smear from one, and two in the other.

In the experiment designed to test the possibility of the contamination during the tracking of the needle, no bacilli were found in smears obtained from the two lepromatous subjects and one patient with dimorphous leprosy. A single bacillus was detected in two others with dimorphous leprosy and three bacilli were found in a borderline case.

TABLE 1

\begin{tabular}{l|c|c|c}
\hline Classification & Examined & $\begin{array}{c}\text { With acid-fast } \\
\text { baccilli in } \\
\text { leucocytes }\end{array}$ & $\begin{array}{c}\text { Total } \\
\text { positive }\end{array}$ \\
\hline Lepromatous & 59 & 8 & 26 \\
Tuberculoid & 22 & 0 & 4 \\
Borderline & 7 & 0 & 4 \\
Dimorphous & 9 & 1 & 5 \\
Indeterminate & 4 & 0 & 3 \\
\hline \multicolumn{1}{c|}{ Total } & 101 & 9 & 42 \\
\hline
\end{tabular}

Among the patients examined, several had a history of leprosy for a duration of two years or under and the lepromatous among these showed a higher incidence of Bacillaemia as shown in Table 2.

\section{Discussion}

In the early stages of the disease, Bacillaemia is common in cases of lepromatous leprosy and can be present in cases who have been under treatment for over two years. In the four positive tuberculoid cases, only one or two bacilli were detected in each.

$M$. leprae are scanty or absent in the material obtained by the needle tracking through the subcutaneous tissue.

Those patients who had bacilli within the leucocytes, had had little or no treatment at the time of the investigation. 
AN INVESTIGATION INTO BACILLAEMIA IN LEPROSY

COLOURED ILLUSTRATIONS TO THIS PAPER BY R. RHODES-JONES OVERLEAF 

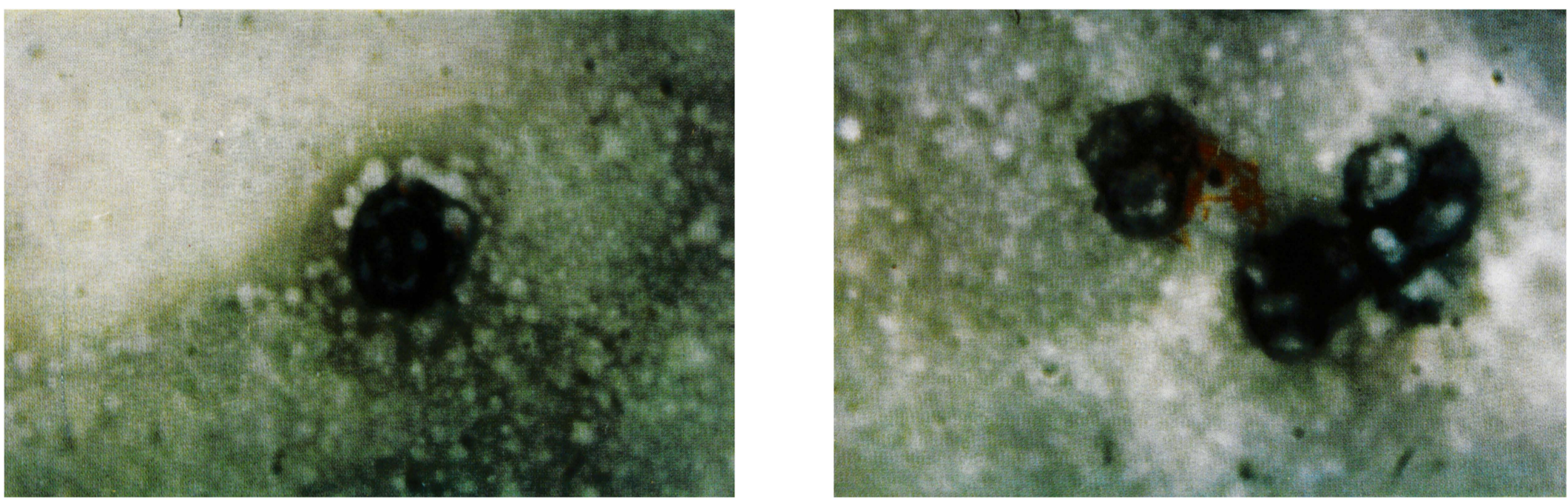

Examples of Acid-Fast Bacilli in Venous Blood of Leprosy Patients. 
AN INVESTIGATION INTO BACILLAEMIA IN LEPROSY
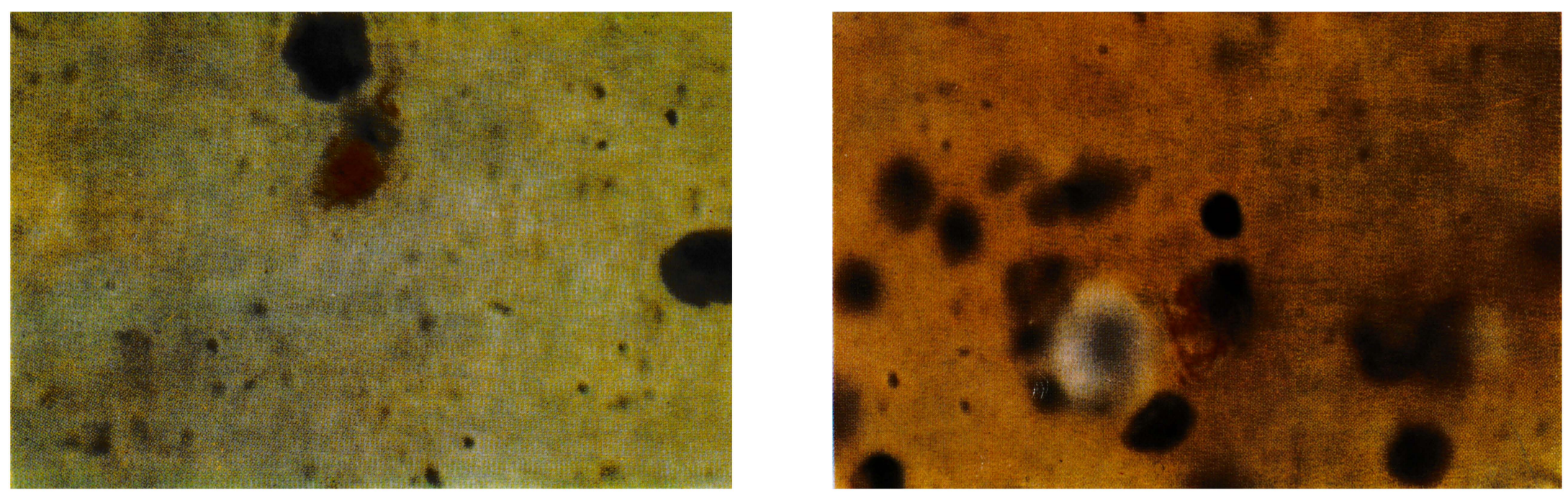

Examples of Acid - Fast Bacilli in Venous Blood of Leprosy Patients. 
LEPROSY REVII:W 
TABLE 2

\begin{tabular}{l|c|c|c}
\hline Classification & Examined & $\begin{array}{c}\text { With acid-fast } \\
\text { bacilli in } \\
\text { leucocytes }\end{array}$ & $\begin{array}{c}\text { Total } \\
\text { positive }\end{array}$ \\
\hline Lepromatous & 14 & 8 & 13 \\
Tuberculoid & 12 & 0 & 1 \\
Borderline & 1 & 0 & 0 \\
Dimorphous & 6 & 1 & 3 \\
Indeterminate & 3 & 0 & 2 \\
\hline \multicolumn{1}{c|}{ Total } & 36 & 9 & 19 \\
\hline
\end{tabular}

\section{Summary}

Venous blood from 101 cases of leprosy was examined for bacillaemia and of these, 42 were positive.

An attempt was made to evaluate the possibility of contamination of the needle by bacilli in the skin.

\section{Acknowledgments}

I wish to thank Dr. John Garrod for his encouragement while carrying out these investigations, Dr. R. F. MacKnight for the surgery, Dr. D. H. H. Robertson for his advice in the preparation of this paper, Mr. Justo Obwa for technical assistance, Mrs. J. Rhodes-Jones for the microphotography and the Secretary-General of the East African Common Services Organisation for permission to publish.

\section{References}

IYENGAR, K. R. K. (1919 Indian Journal Med. Res., 7,235.

LOWE, J. (1933), Indian Med. Gazette, 68, 503.

Manson-BAhr, P. H, (1954), Manson's Tropical Diseases, 14th edn., 568.

RHodes-Jones, R. (1954), Lep. Review, 30, 251.

*Shtein, A. A. and Tutrevich, L. M. (1957) Abstract Lep. Review, 1959, 30, 263.

* Attempts to obtain the original article were unsuccessful. 